\title{
LEIBNIZ
} SOGENANNTE

MONADOLOGIE UND

\section{PRINCIPES DE LA NATURE ET DE LA GRACE FONDÉS EN RAISON}

HERAUSGEGEBEN VON

CLARA STRACK

ALS MANUSKRIPT GEDRUCKT 


\section{Unveränderter photomechanischer Nachdruck}

1967 by Walter de Gruyter \& Co., vormals G. J. Göschen'sene Verlagshandlung -

J. Guttentag, Verlagsbuchhandlung - Georg Reimer - Karl J. Trübner - Veit \& Comp., Berlin 30

Printed in Germany

Obne ausdruickliche Genehmigung des Verlages ist es nicht gestattet, dieses Buch oder Teile daraus auf photomechanischem Wege (Photokopie, Mikrokopie) zu vervielfältigen 